\section{International Scientific Journal Theoretical \& Applied Science}

p-ISSN: 2308-4944 (print) e-ISSN: 2409-0085 (online)

Year: $2018 \quad$ Issue: 03 Volume: 59

Published: $30.03 .2018 \quad$ http://T-Science.org
Venera Sharshenbekovna Tabaldieva doctor of juridical science professor of Kyrgyz-Russian slavic university

Baktibek Madanbekovich Alimbekov candidate of juridical science, doctoral student of Kyrgyz-Russian slavic university

SECTION 32. Jurisprudence.

\title{
ISSUES OF IMPROVING THE ORGANIZATION OF INFORMATION AND ANALYTICAL WORK OF LAW ENFORCEMENT ACTIVITY BODIES OF INTERNAL AFFAIRS OF THE KYRGYZ REPUBLIC
}

Abstract: The article deals with the main issues of information in the law enforcement activities of the internal affairs bodies: its significance, role and place in the work of the police. In addition, types of information are considered, specifying each of them.

Key words: information, law enforcement activity of law enforcement bodies, information work, analytical work.

Language: Russian

Citation: Tabaldieva VS, Alimbekov BM (2018) ISSUES OF IMPROVING THE ORGANIZATION OF INFORMATION AND ANALYTICAL WORK OF LAW ENFORCEMENT ACTIVITY BODIES OF INTERNAL AFFAIRS OF THE KYRGYZ REPUBLIC. ISJ Theoretical \& Applied Science, 03 (59): $227-230$.

Soi: http://s-o-i.org/1.1/TAS-03-59-38 Doi: crossef https://dx.doi.org/10.15863/TAS.2018.03.59.38

\section{ВОПРОСЫ СОВЕРШЕНСТВОВАНИЯ ОРГАНИЗАЦИИ ИНФОРМАЦИОННОЙ И АНАЛИТИЧЕСКОЙ РАБОТЫ ПРАВООХРАНИТЕЛЬНОЙ ДЕЯТЕЛЬНОСТИ ОРГАНОВ ВНУТРЕННИХ ДЕЛ КЫРГЫЗСКОЙ РЕСПУБЛИКИ}

Аннотация: В статье рассматриваются основнье вопросы информаџии в правоохранительной деятельности органов внутренних дел: ее значение, роли и место в деятельности ОВД. Кроме этого рассмотрены виды информации, с указанием особенной каждой из них.

Ключевые слова: информация, правоохранительная деятельность органов внутренних дел, информационная работа, аналитическая работа.

\section{Introduction}

В правоохранительной деятельности органов внутренних дел организация информационной и аналитической работы играют исключительно важную роль. Это объясняется тем, что указанные виды деятельности, будучи органической частью управления, является как бы его исполнительной средой.

Информация, понимаемая как социальная память, накапливаемое знание, с возрастанием темпов общественного развития и научнотехнической революции превратилась в стратегический ресурс человечества. Этот ресурс неисчерпаем, так как при потреблении он не сокращается, а, наоборот, возрастает [1, с. 95 106]. Общепризнано, что общество не может развиваться без трех важнейших компонентов: материально-технических средств, трудовых ресурсов и современной информации.
Человечество, взаимодействуя с окружающей средой, формирует внутри себя в результате процессов отражения и познания информационную модель мира. От того, как рационально и эффективно налажена организация информации в обществе, зависит прогресс производства, науки, техники, культуры.

\section{Materials and Methods}

По мнению С.А. Афанасьева, А Д. Урсула М.И. Брагинского, И.Л. Бродского, А.В. Виноградова, Ю.А Тихомирова и рада других ученых, информацию можно представить как одну из сторон отражательных процессов, как форму проявления и материал отражения. Следует иметь в виду, что при восприятии объективной действительности человек получает знания о ней в виде сведений (данных), которые в 
результате их передачи другим лицам становятся сообщениями. Лишь при использовании любых сведений и сообщений для решения человеком конкретных задач эти знания становятся информацией.

Правоохранительный орган должен быть информирован «о сущности и конкретных проявлениях объективных закономерностей, которые действуют в сфере общественной жизни, являющейся компетенцией этого органа; о механизмах действия этих законов; о методах и формах, которые нужно применять в целях их благоприятного использования для решения управленческих задач; об общих целях, стоящих перед обществом на данном этапе его развития, и о задачах, которые призван решать орган, чтобы способствовать достижению общих целей» $[2$, с. 180].

Любой человеческий труд немыслим без информационных процессов, но нигде так не велико значение информации, как в правоохранительной деятельности органов внутренних дел. Здесь информация выступает и как предмет труда (например, статистические данные), и как средство воздействий (например, приказ), и как средство обратной связи (например, отчет), и как продукт труда (например, аналитическая справка).

«По мнению В. Г. Афанасьева, именно благодаря информационным процессам система способна осуществить целесообразное взаимодействие с окружающими условиями, координировать и субординировать отношения собственных компонентов, направлять их движение, равно как и движение себя самой, как целого к заранее запрограммированной цели» [3, c. 111$]$.

С учетом изложенного можно отметить, что для успешного выполнения своих функций органы внутренних дел должны быть осведомлены о состоянии общественного порядка и криминогенной обстановки, т. е. о том, что вызывает необходимость соответствующего воздействия и как его осуществить. Все это достигается организацией и осуществлением непрерывного обмена информацией, как между компонентами системы, так и между системой и внешней средой. На основе собранной, определенным образом обработанной и осмысленной информации принимаются решения, передаваемые исполнительным органам. Применительно к обеспечению нормального функционирования правоохранительной деятельности органов внутренних дел и в дальнейшем его совершенствования по нашему, во-первых, необходима информация о состоянии преступности. Далее следует осуществить переработку информации с целью формулирования задач для низовых территориальных органов, необходимо также обеспечить контроль за их реализацией.

Процесс создания информационных систем, активизировавшийся с внедрением в них средств автоматизации, поставил перед правом совершенно новые либо недостаточно разработанные теорией проблемы [5, с. 108]. В тот период правовая наука, по сути дела, оказалась не готовой к решению проблем нормального обеспечения современных информационных систем. Сейчас этот теоретический пробел в юридической науке в значительной мере восполняется работами М. И. Брагинского, И. Л. Бродского, А. В. Венгерова, В. Г. Вишнякова, Ю. А. Тихомирова, В. В. Толстошеева, А. М. Яковлева и ряда других ученых [6, с. $21 ; 7$, с. 184].

От полноты, достоверности и своевременности информации зависят правильность оценки оперативной обстановки, оптимальность принимаемых решений, целеустремленность планирования мероприятий, четкость доведения задач до исполнителей, эффективность контроля. Следовательно, без четкой системы информации, подразделения, осуществляющие борьбу с преступностью, не могут успешно решать возложенные на них задачи. Это обстоятельство, по нашему мнению, обусловливает необходимость как упорядочения системы информации подразделений МВД Кыргызской Республики сверху до низу, так и ее совершенствование, что является необходимым условием реформы правоохранительной деятельности органов внутренних дел Кыргызской Республики в целом.

В связи с этим, следует отметить, что за последние годы МВД Кыргызской Республики проделана значительная работа в этом направлении: -приняты меры по улучшению планирования;

- введена новая статистической отчетности;

- установлена единая структура отчетных документов;

определен порядок поступления внеочередной оперативной информации.

Совершенствовалась и технически оснащались информационно-аналитической службы. Осуществлен также ряд организационных мер, направленных на совершенствование информационной работы, например в системе МВД Кыргызской Республики создан организационноаналитический отдел. Функции, которого заключаются в сборе информации, его анализе и прогнозировании.

Вместе с тем, эти меры, как мы отмечаем, в большей степени касаются непосредственно центрального аппарата МВД Кыргызской 
Республики. На местах до сих пор отсутствует четкая система информации, отвечающая современным требованиям научной организации правоохранительной деятельности органов внутренних дел $[8$, с. 134]. Хотя именно информация, циркулирующая на местах, является, на наш взгляд, фундаментом всей информационной системы подразделений МВД Кыргызской Республики. В связи с чем, по нашему мнению, начинать необходимо с низовых подразделений, то есть с основания, без которого немыслимо успешное построение информационной системы.

Говоря об информационном обеспечении, хотелось бы отметить, что в соответствии с общими положениями теории система должна располагать управляющей и осведомительной информацией. Содержание управляющей и осведомительной информации охватывает всю совокупность сведений, необходимых для нормального функционирования подразделений МВД Кыргызской Республики, осуществляющих борьбу с преступностью. Эти сведения служат основой для правоохранительной деятельности органов внутренних дел в их взаимосвязи и взаимодействии. Осведомительная информация важна для обеспечения их деятельности [9]. Поэтому отсутствие или недостаток информации приводит к нарушению нормального функционирования системы в целом.

Управляющая информация должна оцениваться с точки зрения ее ценности, которая измеряется ее важностью для правоохранительной деятельности подразделений МВД КР. Поступая от Президента Кыргызской Республики, Правительства Кыргызской Республики, руководства МВД КР, в УБОП МВД КР, управляющая информация определяет стратегию ее деятельности и составляет правовую основу ее функционирования.

\section{Conclusion}

Для реализации задач, предписываемых управляющей информацией, службы и отделы МВД КР должны собирать, накапливать и перерабатывать осведомительную информацию, то есть информацию непосредственно, касающуюся преступности (формирования их руководителем, их ресурсное обеспечение и т.д.) и выдавать ее сотрудникам, осуществляющим борьбу с преступностью с учетом их функциональных обязанностей. Только при такой взаимосвязи управляющей и осведомительной информации, при разумном их сочетании МВД КР в состоянии эффективно обеспечить свою деятельность.

Управляющая информация, как правило, носит документальный характер, поэтому поступающие в подразделения МВД КР, документы принимаются, фиксируются в соответствии с номенклатурой дел в журналах, рассматриваются руководством, распределяются среди исполнителей, а также устанавливается контроль за их качеством и своевременностью исполнения.

Говоря о действенности информации, полагаем, что она зависит прежде всего от ее качества. Избыток информации, как и ее недостаток, также не способствует эффективности правоохранительной деятельности органов внутренних дел. По справедливому замечанию В. Г. Афанасьева «информацию составляет та часть знания, которая используется для ориентировки, для активного действия, для управления, т.е. в целях сохранения качественной специфики, совершенствования и развития системы» $[4$, с. 33].

Вместе с тем, в практической деятельности не редки факты, когда отдельные руководители вышестоящих подразделений действуют по принципу: чем большой поток информации поступает в подчиненные органы, тем лучше [10]. При этом не всегда обеспечивается ее качество и не учитывается тот факт, что обеспечение информацией - не самоцель, а средство, необходимое для подготовки и принятия рациональных решений. Более того, этот поток управляющей информации, в отличие от осведомительной, поступает вопреки желанию его руководителя. Порой в силу низкого качества, неконкретности и дублирования она не используется для выработки соответствующих решений, например, было несколько вариантов реформы правоохранительной деятельности органов внутренних дел.

В связи с этим, такая информация не только не бесполезна, но и вредна, так как на ее получение, изучение и другие операции нерационально затрачивается значительное время. 


\begin{tabular}{l|lr|ll|ll} 
& ISRA (India) & $=\mathbf{1 . 3 4 4}$ & SIS (USA) & $=\mathbf{0 . 9 1 2}$ & ICV (Poland) & $=\mathbf{6 . 6 3 0}$ \\
Impact Factor: & ISI (Dubai, UAE) $=\mathbf{0 . 8 2 9}$ & PUHL (Russia) $=\mathbf{0 . 2 0 7}$ & PIF (India) & $=\mathbf{1 . 9 4 0}$ \\
& GIIF (Australia) & $=\mathbf{0 . 5 6 4}$ & ESJI (KZ) & $=4.102$ & IBI (India) & $=\mathbf{4 . 2 6 0}$ \\
& JIF & $=\mathbf{1 . 5 0 0}$ & SJIF (Morocco) & $=2.031$ & & \\
\hline
\end{tabular}

\section{References:}

1. Vinogradov V. A. (1983) Informaciya i global'nye problemy sovremennosti // Voprosy filosofii. 1983. № 12. - p. 95-106.

2. Varlen M. (2002) Novye aspekty instituta rossijskogo grazhdanstva. // Zakonnost'. 2002. №12. - p. 5.

3. Gabrichidze B.N. (1982) Konstitucionnyj status organov sovetskogo gosudarstva. - M., 1982. p. 9.

4. (2004) Ugolovnyj process: Uchebnik. // Pod red. V.P. Bozh'eva. 4-e izd., pererab. i dop. M., 2004. - p. 32.

5. Ipokyan A.P. (1971) Podgotovka i praktika upravlencheskih reshenij $\mathrm{v}$ organah vnutrennih del. M., 1971. - p. 108

6. Braginskij M.I. (1972) Kollegial'nost' i edinonachalie $\mathrm{v}$ upravlenii organami vnutrennih del. M., 1972. - p. 21.
7. Brodskij I.L. (2006) Funkcii organov upravleniya. M.: YUrid. lit., 2006. - p. 184.

8. Atamanchuk G.V. (2014) Teoreticheskie osnovy organizacii upravlencheskogo truda. Ryazan', 2014. - p. 134.

9. Strel'cov A.A. (2006) O proekte Strategii razvitiya informacionnogo obshchestva $v$ Rosii. Available:

http://zhenilo.narod.ru/main/ips/2006 common _problems.pdf (Accessed: 10.03.2018).

10. Strel'cov A.A. (2018) Teoreticheskie, organizacionnye, uchebno-metodicheskie i pravovye problemy strategii razvitiya informacionnogo obshchestva $\mathrm{v}$ Rossii. Available: http://libed.ru/knigi-nauka/4470662-teoreticheskie-organizacionnie-uchebnometodicheskie-pravovie-problemi-proektestrategii-razvitiya-informacionnogo.php. (Accessed: 10.03.2018). 